\title{
Comparison of Perioperative Blood Loss with and without Tranexamic Acid in Hip Arthroplasty
}

Sanum Kashif ${ }^{1^{*}}$, Zahid Khan ${ }^{2}$

\begin{abstract}
Objective: To compare the perioperative blood loss in patients undergoing hip arthroplasty for femur neck fractures with and without administering tranexamic acid before surgical incision.

Study Design: Comparative Interventional study.

Place and Duration of Study: The study was conducted at Orthopedic Department of Indus Hospital Karachi, from $1^{\text {st }}$ January to $30^{\text {th }}$ June 2015.

Materials and Methods: After ethical committee approval, sixty patients, scheduled for hip arthroplasty were included in this study. Patients were randomly allocated into two groups. Thirty patients in Group A (Tranexamic acid) treated with tranexamic acid with $15 \mathrm{mg} / \mathrm{kg}$ dose in $10 \mathrm{ml}$ syringe and Group B were given an equal volume of saline before surgery. In both groups, blood loss was calculated. The need for blood transfusion as well as the amount of blood required was also noted. In both the groups, hematocrit was measured on $5^{\text {th }}$ post-operative.

Results: A total of sixty patients (mean age $65.33 \pm 9.50$ years), scheduled for hip arthroplasty, were included. There were $26(43.3 \%)$ male and 34 (56.7\%) female patients. Patients were divided into two equal groups, Group A (Tranexamic acid) and Group B (Normal Saline). Postoperative mean estimated blood loss was significantly reduced in Group A than group B (203.8 \pm 141.81 vs. $281.6 \pm 130.31 p=0.031$ ).
\end{abstract}

Conclusion: Tranexamic acid is a cost-effective and safe means of minimizing perioperative blood loss and reduction in hemoglobin concentration in hip arthroplasty.

Key Words: Blood Loss, Hemoglobin Level, Hip Arthroplasty, Postoperative, Tranexamic Acid.

How to cite this: Kashif S, Khan Z. Comparison of Perioperative Blood Loss with and without Tranexamic Acid in Hip Arthroplasty. Life and Science. 2022; 3(1): 20-24. doi: http://doi.org/10.37185/LnS.1.1.196

This is an Open Access article distributed under the terms of the Creative Commons Attribution License (http://creativecommons.org/licenses/by/4.0), which permits unrestricted use, distribution, and reproduction in any medium, provided the original work is properly cited.

\section{Introduction}

Hip fractures are devastating injuries that affect both the health care system and society. Treatment options for hip fractures are manipulation and closed reduction of femoral neck fractures. ${ }^{1}$ Open reduction is performed only when patient is not a good candidate for hemiarthroplasty with a femoral head prosthesis and when closed reduction is not possible. ${ }^{2}$ Indications of hemiarthroplasty in intra capsular femur neck fractures are when a fracture cannot be satisfactorily reduced or fixed with

${ }^{1}$ Department of Anesthesia/ Orthopedics2

Frontier Crops Hospital, Quetta

Correspondence:

Dr. Sanum Kashif

Assistant Professor, Anesthesia

Frontier Crops Hospital, Quetta

E-mail: sanumdr@gmail.com

Funding Source: NIL; Conflict of Interest: NIL

Received: Mar 25, 2021; Revised: Sep 04, 2021

Accepted: Nov 24, 2021

20 stability. Complications that can arise from hip surgeries include blood loss. It is essential to reduce perioperative blood loss, to avoid transfusions, reopening and postoperative anemia that could lead to congestive heart failure, delayed wound healing, mobilization, and other complications., According to one of the local study, among 416 knee replacement surgeries, tranexamic acid was used in $162(74 \%)$ patients and was not used in 92(36\%). When it was used, only $26(16 \%)$ patients required blood transfusion, but when it was not used, $35(39.1 \%)$ required transfusion $(p<0.05) .^{5}$

In a resource poor countries, different techniques generally used to reduce the risk of perioperative allogeneic blood transfusion in hip surgery such as preoperative autologous blood donation, intra- and postoperative red blood cell salvage, controlled hypotension, normovolemic haemodilution, or lowering the transfusion trigger are either not 
available, too time consuming or require expensive device that are not available. ${ }^{6,7}$ Furthermore, the risk of poor blood quality increases, especially if postoperatively salvaged but untreated blood is used. Tranexamic acid (TXA) is an antifibrinolytic that inhibits conversion of plasminogen to plasmin, thus preventing clot break-down. Since 1960s, TXA has been used to control bleeding safely. TXA has been shown to reduce bleeding and transfusion requirements without increasing thromboembolic complications and decreases overall mortality. ${ }^{8}$ This study is design to compare mean blood loss with and without Tranexamic acid (TA) in patients undergoing hip Arthroplasty to prevent exposure of blood transfusion related hazards to the patient.

\section{Materials and Methods}

This comparative study was conducted at Orthopedic Department of Indus Hospital Karachi from $1^{\text {st }}$ January to $30^{\text {th }}$ June 2015 . After ethical committee approval, 60 patients (calculated by WHO sample size calculator), of either gender between 40 80 years of age group, undergoing hip arthroplasty were included. Patients with known bleeding disorder, ischemic heart disease and allergic to tranexamic acid, were excluded. Patients who have given informed consent to participate in the study were randomized into one of the two study arms before the start of surgery. The surgical team opened the sealed envelopes provided by the Indus Hospital Research Center's Clinical Research Unit (CRU) that provides the study arm allocation. According to SNOSE protocol i.e., envelopes were numbered sequentially and sealed. Patients study identifier, date and signature was mentioned on the front of the envelope. The envelope contained carbon paper which transfers the patient identifier, date and signature to the treatment allocation paper inside. Group A received Tranexamic acid (15 mg/kg) group (in $10 \mathrm{ml}$ syringe) and Group B was also given an equal volume of saline in a slow infusion 5 to 10 minutes before surgery by resident not part of the study team.

In both the groups, baseline characteristics such as age, gender, pre-surgery $\mathrm{Hb}$ and hematocrit as well weight and height were noted from the medical records on a pre-coded questionnaire. Blood loss was calculated and the need for blood transfusion as well as the amount of blood required was also be noted. In both the groups, hematocrit was again measured on day 5. Protocol for iv fluids and pain medications for these patients was standardized with help from department of anesthesia.

Mean \pm Standard deviation was calculated for age, weight, Height, preoperative and post operative $\mathrm{Hb} \%$ and Hematocrit levels and outcome variable i.e. postoperative Blood loss in both groups. Frequency percentage was calculated for gender. Student TTest was applied to compare the postoperative mean blood loss in both groups. Confounders was controlled through stratification of age, weight, h , gender, preoperative and postoperative $\mathrm{Hb} \%$ and HCT levels, and determine their effects on outcome variables.

\section{Results}

A total of 60 patients, scheduled for hip arthroplasty, were randomly allocated into two groups. Thirty patients in Group A received tranexamic acid (15 $\mathrm{mg} / \mathrm{kg}$ ) and Group B received equal volume of saline in a slow infusion, 10 minutes before surgery. The average age of the patients was $65.33 \pm 9.50$ years. Both groups were comparable for age, weight, height and duration of fracture (Table 1).

\begin{tabular}{|c|c|c|c|}
\hline Variables & $\begin{array}{l}\text { Group A } \\
n=30\end{array}$ & $\begin{array}{l}\text { Group B } \\
n=30\end{array}$ & $\begin{array}{c}P \text { - } \\
\text { Value }\end{array}$ \\
\hline Age (Years) & $64.93 \pm 9.10$ & $65.73 \pm 10.03$ & 0.74 \\
\hline Weight (kg) & $68.20 \pm 5.54$ & $70.27 \pm 6.71$ & 0.19 \\
\hline Height (cm) & $164.50 \pm 7.81$ & $166 \pm 6.96$ & 0.43 \\
\hline $\begin{array}{l}\text { Duration of } \\
\text { Fracture (days) }\end{array}$ & $10.70 \pm 4.69$ & $9.60 \pm 5.13$ & 0.39 \\
\hline \multicolumn{4}{|c|}{ Independent sample t test } \\
\hline
\end{tabular}

There were $43.3 \%(26 / 60)$ male and $56.7 \%(34 / 60)$ female.

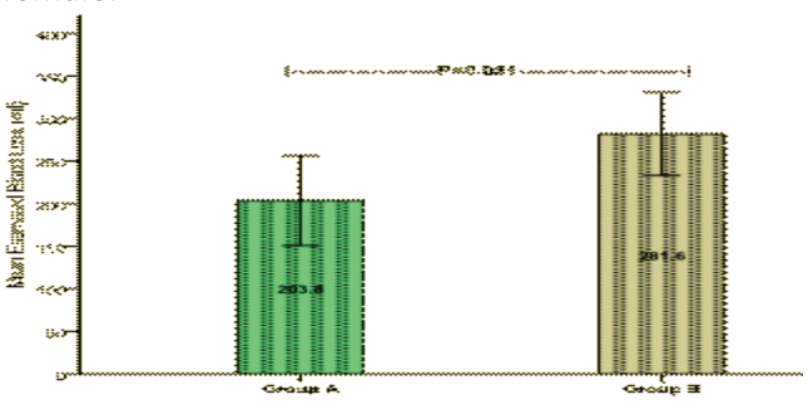

Fig-1: Comparison of Mean Estimated Blood Loss between groups

Mean and SD of estimated blood loss

Group A $=203.8 \pm 141.81 \mathrm{ml}$

Group B = 281.6 $\pm 130.31 \mathrm{ml}$

Independent sample t-test=-2.215; $P=0.031$ 
Pre and postoperative mean hemoglobin level was not significant between groups. Preoperative hematocrit was not significant between groups while postoperative hematocrit was significant between groups (Table 2).

\begin{tabular}{llll}
\hline \multicolumn{3}{l}{ Table 2: Comparison of Mean Hb And HCT Between } \\
Groups \\
\hline Variables & Group A & $\begin{array}{l}\text { Group B } \\
\mathbf{n = 3 0}\end{array}$ & P-Value \\
& $\mathbf{n}=\mathbf{3 0}$ & \\
Pre Hb (\%) & $10.40 \pm 0.69$ & $10.36 \pm 0.56$ & 0.77 \\
Post Hb (\%) & $11.13 \pm 0.86$ & $10.88 \pm 0.68$ & 0.23 \\
Pre HCT & $38.65 \pm 3.78$ & $39.13 \pm 5.36$ & 0.69 \\
Post HCT & $32.60 \pm 4.02$ & $30.17 \pm 4.40$ & 0.029 \\
Independent sample t test & & \\
\hline
\end{tabular}

Comparison of mean estimated blood loss between groups is shown in (Fig 1), mean estimated blood loss was significantly reduced in group $A$ than group $B$ (203.8 \pm 141.81 vs. $281.6 \pm 130.31 p=0.031$ ).

Stratification analysis was also performed and observed that mean estimated blood loss was not significant between group for below and equal to 60 years and 71 to 80 years of age groups patients. Similarly mean blood loss was not significantly different for both gender and duration of fracture between groups.

\section{Discussion}

Tranexamic acid inhibits fibrinolysis, by blocking the lysine binding sites of plasminogen, as plasminogen binds to fibrin at this site that results in clot breakdown. Tissue plasminogen activator is the enzyme, responsible for plasminogen conversion to active plasmin. Cole $\mathrm{E}$ et al; showed in multivariate analysis, Tranexamic acid independently associated with a reduction in multiorgan failure [odds ratio $(\mathrm{OR})=0.27$, confidence interval $(\mathrm{Cl}): 0.10-0.73, P=$ $0.01]$ and was protective $(\mathrm{OR}=0.16 \mathrm{Cl}: 0.03-0.86, P=$ 0.03 ) in shocked patients. ${ }^{9}$

Kayupov et al compared oral and intravenous tranexamic acid in terms of reduction of blood loss and found that mean reduction of hemoglobin was similar between oral and intravenous groups (3.67 $\mathrm{g} / \mathrm{dL}$ compared with $3.53 \mathrm{~g} / \mathrm{dL} ; p=0.0008$, equivalence). The mean blood loss was equivalent between oral and intravenous administration (1,339 $\mathrm{mL}$ compared with $1,301 \mathrm{~mL} ; p=0.034$, equivalence). ${ }^{10}$ Yiting Lei $\mathrm{MM}$ et al compared multiple doses of Intravenous tranexamic acid to assess blood loss in total hip arthroplasty in $\mathbf{1 5 0}$ patients and found that mean hidden blood loss, total blood loss and maximum $\mathrm{Hb}$ drop were significantly lower in group $C$ (received 4 doses) at 3hours interval as compared to group $B$ and group $A$ (received 3 and 2 doses respectively) and no patient underwent blood transfusion during hospitalization. ${ }^{11}$ According to Yi-ming Qi et al, metaanalysis showed significant differences with respect to transfusion rate of allogeneic blood [risk ratio (RR) $=0.66,95 \%$ confidence interval $(\mathrm{Cl}): 0.56$ to $0.78, P=$ 0.003 ], intraoperative blood loss ( $\mathrm{MD}=-76.63,95 \%$ Cl: -139.55 to $-13.71, P=0.02$ ), total blood loss [mean difference $(\mathrm{MD})=-273.00,95 \% \mathrm{Cl}:-353.15$ to $-192.84, P<0.00001$ ] postoperative blood loss (MD $=-125.29,95 \% \mathrm{Cl}:-221.96$ to $-28.62, P=0.01)$ and postoperative hemoglobin ( $\mathrm{MD}=0.80,95 \% \mathrm{Cl}$ : 0.38 to $1.22, P=0.0002$ ) in tranexamic acid group versus placebo group. ${ }^{12}$ Yale $A$ et al, in journal of Arthroplasty showed strong evidence in support of the use of TXA to reduce blood loss and risk of transfusion after primary total hip arthroplasty. ${ }^{13}$ Wenming Jiang and Liyong Shang, $\mathrm{MB}$, a total of five RCTs with 584 patients (TXA group $=289$, control group $=298$ ) were included in the meta-analysis. Based on the results, administration of TXA was associated with a reduction in total blood loss, blood loss in drainage, need for transfusion, length of hospital stay, and occurrence of hematoma $(P<.05)$. Administration of TXA increased the hemoglobin level at 3 days after surgery $(P<.05){ }^{14}$ Huang et al compared 3 groups, in respect to perioperative blood loss, $\mathrm{Hb}$ level decline, requirement of transfusion, IL-6 and CRP levels post-operatively. Patients who received TXA, intravenously or topically, without use of tourniquet had less blood loss, less knee swelling and pain post-operatively, low inflammatory biomarkers, and better satisfaction than those patients who were treated with a tourniquet. ${ }^{15}$ Recent study from Acta Orthopaedica Belgica compared efficacy of tranexamic acid in terms of route of administration and showed that calculated blood loss was slightly lower with topical TXA but the difference was not statistically significant. Thus, topical TXA was found as effective as IV and oral TXA in terms of reducing perioperative blood loss in primary TKA and THA. ${ }^{16,17}$ Study from Journal of Medical Association Thai showed that in patients who underwent unilateral 
cemented total knee arthroplasty, no difference was found in postoperative $\mathrm{Hb}$ and Hct levels at 12 hours between groups, the mean decreasing $\mathrm{Hb}$ and $\mathrm{HCT}$ in the TXA group was significantly lower than in the control group $(p<0.001) .{ }^{18}$ Maitreyee Mukherjee et al, compared the efficacy of tranexamic acid and epsilon aminocaproic acid in reduction of perioperative blood loss in femoral surgeries and showed that blood loss intra-operatively was 323.28 $\pm 45.282 \mathrm{ml}$ in Group $\mathrm{T}$ and $411.67 \pm 41.384 \mathrm{ml}$ in Group E $(p<0.001)$. Postoperative blood loss was $134.48 \pm 42.476 \mathrm{ml}$ in Group T and $130.00 \pm 44.721$ $\mathrm{ml}$ in Group E. Intra-operative blood transfusion was $0.10 \pm .310$ units in Group $T$ and $0.33 \pm .479$ units in Group E $(p=0.03) .{ }^{19}$ Digas $\mathrm{G}$ et al, did study on blood loss following primary total knee arthroplasty (TKA) and compared the efficacy of intravenous and topical tranexamic acid (TXA) with the control group. The mean blood loss in drain, in control, IV and intraarticular groups was $415 \pm 24,192 \pm 21$ and $121 \pm 17$ $\mathrm{ml}$, respectively. About $23 \%$ (IV) and $17 \%$ (intraarticular) $43 \%$ (control), required blood transfusion. Preoperative $\mathrm{Hb}$ values reduced at $24 \mathrm{~h}$ by $2.80 \pm$ $0.14,2.24 \pm 0.17$ and $2.26 \pm 0.18 \mathrm{mg} / \mathrm{dl}$, respectively. Median volume of blood in drain was less in group, who received TXA $(500.00 \mathrm{~mL})$ than in control group $(900.00 \mathrm{~mL})(p<0.05)[95 \% \mathrm{Cl}(-525.00)$ to $(-$ 300.00)]. The median drop in $\mathrm{Hb}, 12 \mathrm{~h}$ postoperatively was less in patients, who received TXA $(2.10 \mathrm{~g} / \mathrm{dL})$ than in control group $(3.10 \mathrm{~g} / \mathrm{dL})(p<$ $0.05)$ [95\% Cl $(-1.60)$ to $(-0.60)] .^{20}$ According to study in Annals of Translation Medicine, multimodal approaches to patient blood management in TKR have proven some progress to enhance early patient recovery including the control of the transfusion rate and the postoperative blood loss. Intraarticular use of TXA helps the surgeon in hemostasis control with proven efficacy and safety. ${ }^{21}$ Gauden EB et al showed efficacy of tranexamic acid in reducing blood loss in hip fracture patients and found that TXA has the potential to decrease transfusion rates by reducing the blood loss in hip fractures, which helps in early recovery and discharge of patients with hip fractures every year. ${ }^{22}$ Several other studies by Lee and Tengberg PT also showed the effect of TXA use on postoperative transfusion rates and hemoglobin $(\mathrm{Hb})$ levels following hemiarthroplasty and found that patients who received TXA had lower rate of transfusion (6\% vs. $19 \% . p=0.005)$ and less drop in hemoglobin on first post-operative day (26\% vs. $42 \%$; $p=0.014)$. One transfusion was prevented in every 8 patients, who received tranexamic acid prophylactically. ${ }^{23,24}$

\section{Conclusion}

Tranexamic acid is a cost-effective and safe means of minimizing perioperative blood loss and reduction in hemoglobin concentration in hip arthroplasty.

\section{REFERENCES}

1. Iqbal MZ, Azeem M, Malik MR, Ch NA. Evaluation of Risk Factors of Hip Fractures; A Retrospective Study. Journal of Pakistan Orthopaedic Association. 2014 ; 26: 15-9.

2. Khan SH, Ara I, Raza S, Sipra S. Functional outcome of surgery in patients with acetabular fractures. J Ayub Med Coll Abbottabad. 2013; 25: 60-3.

3. Tosounidis TH, Castillo R, Kanakaris NK, Giannoudis PV. Common complications in hip fracture surgery: Tips/tricks and solutions to avoid them. Injury. 2015 ; 46: S3-11.

4. Hansson S, Rolfson O, Åkesson K, Nemes S, Leonardsson O, Rogmark C. Complications and patient-reported outcome after hip fracture. A consecutive annual cohort study of 664 patients. Injury. 2015; 46: 2206-11.

5. Aslam KS, Niazi AK, Nabi O. Efficacy of tranexamic acid in reducing blood loss in total knee replacements. J Pak Med Assoc. 2015; 65: S210-4.

6. Wong S, Tang H, de Steiger R. Blood management in total hip replacement: an analysis of factors associated with allogenic blood transfusion. ANZ J Surg. 2015 ; 85: 461-5.

7. Saleh A, Small T, Pillai AL, Schiltz NK, Klika AK, Barsoum WK. Allogenic blood transfusion following total hip arthroplasty: results from the nationwide inpatient sample, 2000 to 2009. J Bone Joint Surg. American volume. 2014; 96: e155.

8. Roberts I, Prieto-Merino D, Manno D. Mechanism of action of tranexamic acid in bleeding trauma patients: an exploratory analysis of data from the CRASH-2 trial. Crit Care. 2014; 18: 1-5.

9. Cole E, Davenport R, Willett K, Brohi K. Tranexamic acid use in severely injured civilian patients and the effects on outcomes: a prospective cohort study. Ann Surg Open. 2015; 261:390-4.

10. Kayupov E, Fillingham YA, Okroj K, Plummer DR, Moric M, Gerlinger TL, et al. Oral and intravenous tranexamic acid are equivalent at reducing blood loss following total hip arthroplasty: a randomized controlled trial. J Bone Joint Surg Am. 2017; 99: 373-8.

11. Lei Y, Huang $Q$, Huang Z, Xie J, Chen G, Pei F. Multiple-dose intravenous tranexamic acid further reduces hidden blood loss after total hip arthroplasty: a randomized controlled trial. J Arthroplasty. 2018; 33: 2940-5.

12. Qi YM, Wang HP, Li YJ, Ma BB, Xie T, Wang C, et al. The efficacy and safety of intravenous tranexamic acid in hip fracture surgery: a systematic review and meta-analysis. J Orthop Translat. 2019; 19: 1-1.

13. Fillingham YA, Ramkumar DB, Jevsevar DS, Yates AJ, Shores 
$\mathrm{P}$, Mullen $\mathrm{K}$, et al. The efficacy of tranexamic acid in total hip arthroplasty: a network meta-analysis. J Arthroplasty. 2018; 33: 3083-9.

14. Jiang W, Shang L. Tranexamic acid can reduce blood loss in patients undergoing intertrochanteric fracture surgery: A meta-analysis. Medicine. 2019; 98: e14564.

15. Huang Z, Xie X, Li L, Huang Q, Ma J, Shen B, et al. Intravenous and topical tranexamic acid alone are superior to tourniquet use for primary total knee arthroplasty: a prospective, randomized controlled trial. J Bone Joint Surg Am. 2017; 99: 2053-61.

16. Othman Y, Melebeck F, Daubresse F. Tranexamic acid in joint replacement: a randomized trial comparing intravenous oral and topical routes. Acta Orthopædica Belgica. 2020; 86:397-404.

17. Zhang $P$, He J, Fang $Y$, Chen $P$, Liang $Y$, Wang J. Efficacy and safety of intravenous tranexamic acid administration in patients undergoing hip fracture surgery for hemostasis: a meta-analysis. Medicine. 2017; 96: e6940.

18. Numkanisorn S, Chareancholvanich K, Pornrattanamaneewong C. Intravenous tranexamic acid before and after tourniquet use can reduce blood loss and blood transfusion after total knee arthroplasty. J Med Assoc Thai. 2016; 99: 1220-5.

19. Mukherjee M, Biswas C, Chatterjee S, Bandyopadhyay BK.
Comparative study of efficacy of reduction of blood loss by tranexamic acid and epsilon aminocaproic acid for orthopedic femoral surgeries. Anaesth Pain \& Intensive Care. 2016 ; $20: 417-21$.

20. Digas G, Koutsogiannis I, Meletiadis G, Antonopoulou E, Karamoulas V, Bikos C. Intra-articular injection of tranexamic acid reduce blood loss in cemented total knee arthroplasty. J Orthop Surg. 2015; 25: 1181-8.

21. Gómez-Barrena E, Ortega-Andreu M. Widespread of total knee arthroplasty perioperative blood management techniques based on tranexamic acid: barriers and opportunities. Ann Transl Med. 2015; 3: 299.

22. Gausden EB, Garner MR, Warner SJ, Levack A, Nellestein AM, Tedore T, et al. Tranexamic acid in hip fracture patients: a protocol for a randomised, placebo controlled trial on the efficacy of tranexamic acid in reducing blood loss in hip fracture patients. BMJ open. 2016; 6: e010676.

23. Lee C, Freeman R, Edmondson M, Rogers BA. The efficacy of tranexamic acid in hip hemiarthroplasty surgery: an observational cohort study. Injury. 2015; 46: 1978-82.

24. Tengberg PT, Foss NB, Palm H, Kallemose T, Troelsen A. Tranexamic acid reduces blood loss in patients with extracapsular fractures of the hip: results of a randomised controlled trial. Bone Joint J. 2016; 98: 747-53. 